\section{Behavioral contrast under multiple delays of reinforcement*}

\author{
JOHN V. KELLER \\ Laboratory of Psychopharmacology, University of Maryland \\ College Park, Md. 20742
}

Three pigeons were exposed to a procedure in which a delay was imposed between the occurrence of a response and the presentation of reinforcement. With the delay associated with one key color held constant at $3 \mathrm{sec}$, the delay associated with a second color was increased first to $7 \mathrm{sec}$ and then to $12 \mathrm{sec}$. As the delay was lengthened, long response latencies to the stimulus associated with this increase became more frequent, but modal response latency was affected little. Response latencies to the stimulus associated with the unchanged delay, on the other hand, decreased as the delay in the other component was lengthened.

The strength of a response is lessened if, between the time of response emission and the delivery of reinforcement, a "delay" period without a response is imposed. Using a schedule where every response initiated a delay at the end of which reinforcement was presented, Dews (1960), with pigeons, and Azzi, Fix, Keller, \& Rocha e Silva (1964), with rats, noted a sharp reduction in response rate with increasing delay. Azzi et al attributed much of this rate reduction to a lengthening of the pause after reinforcement. Typically the rats did not immediately retum to press the lever after receiving reinforcement. Instead, they paused for a period of time often equal to or greater than the duration of the preceding delay.

The present experiment examined, first, the changes in postreinforcement pause, or latency, that result from a lengthening of reinforcement delay and, second, the extent of differential control of response latency exercised by two stimuli correlated with the same or different reinforcement delays.

\section{METHOD}

The Ss were three male White Carneaux pigeons, maintained at $75 \%$ of their ad lib weights. Pigeon P5 had been used previously in a discrimination-reversal experiment, Pigeon P82 had a history of continuous reinforcement and shock punishment, and the third bird, P10, was experimentally naive.

The experimental chamber was a two-key box (Lehigh Valley, Model $1519 \mathrm{C}$ ). Only the right key was operative, and it could be illuminated from behind with either red or green light. The infrequent responses to the left key had no programmed effect. Automatic scheduling and recording apparatus was used, and

* Manuscript preparation aided by USPHS Grant No. MH-01604-13. I wish to thank Dr. Brett Cole for his advice in the running of this experiment and Dr. F. W. Hegge for his review of the manuscript. cumulative recorder were used to collect all data.

Each daily session ended after the delivery of 60 reinforcements. In the first five sessions, key pecks were immediately followed by the presentation of mixed grain for $3 \mathrm{sec}$. During reinforcement the houselights and key light were turned off, and the food hopper was illuminated. Red and green key colors were presented in an irregular order, both appearing 30 times in a session. Changes in key color were made immediately after reinforcement.

In the next five sessions a $3-\mathrm{sec}$ delay was imposed between the occurrence of a response to red or green and the delivery of reinforcement. Then, with the delay associated with one of the stimuli held constant at $3 \mathrm{sec}$, the delay associated with the other stimulus was increased to $7 \mathrm{sec}$ for six sessions and then to $12 \mathrm{sec}$ for six more sessions. For P5 and P10 the stimulus associated with the increased delay was the green light; for P82 it was the red light.

Throughout these steps the delay procedure employed was essentially the same as that used by Skinner (1938, p. $72 \mathrm{ff}$ ), Dews (1960), and Azzi et al (1964). A response started a timer appropriate to the color of the key; at the end of the delay interval, reinforcement was presented. Any responses that occurred during the delay interval were effective only in resetting the timer. Thus, the delay interval specified the minimal time that had to occur between a response and its reinforcement. No stimulus change (or stimulus "support") accompanied the delay.

\section{RESULTS AND DISCUSSION}

In the present experiment the reinforcement schedule programmed in each stimulus component of the multiple schedule can be described as a tandem FR 1 DRO t. The tandem schedule is one in which the response-produced schedule change is not accompanied by a change of digital counters and a Gerbrands stimuli, and the DRO contingency, which in this case was initiated by a single response (FR 1) specifies that reinforcement will not be presented until a certain time, $t$, has elapsed without a response (Reynolds, 1961a). Thus, t corresponds to the delay interval, and its value in each component of the multiple schedule was the manipulated variable.

The dependent variable was response latency, or the time from the end of reinforcement to the emission of the first response. Plotted in Fig. 1 are relative frequency distributions of response latency for the three pigeons under each of the four delay conditions. The distributions for red and green stimuli are quite similar when both are associated with the same delay (either 0 or $3 \mathrm{sec}$ ). With the $3 \mathrm{sec}$ delay, the distributions are less sharply peaked and responses of long latency are more frequent than with immediate reinforcement. As the delay associated with one of the stimuli is lengthened, first to 7 and then to $12 \mathrm{sec}$, the associated latencies continue to show a greater incidence of long values, especially in the $>18-\mathrm{sec}$ category. However, increased delays do not result in a systematic shift in the mode of the latency distributions. Modal response latency has previously been found insensitive to a variety of independent variables (cf. Skinner, 1950; Barry \& Harrison, 1957; Dinsmoor, Hughes, \& Matsuoka, 1958; Keller, 1966).

In showing an increased frequency of long response latencies with lengthened reinforcement delay, these data are like those reported by Chung \& Neuringer (1967) and by Shull (1970). These investigators used a tandem FR 1 FI schedule of reinforcement and observed latency to the first response (postreinforcement pause) to be an increasing function of the length of the fixed interval. The present procedure differs in its use of a DRO, instead of an FI, as the terminal link of the tandem schedule. That lengthened DROs, like lengthened FIs, increase postreinforcement pause is in accord with Shull's (in press) most recent findings that suggest that the latency to the first response in FI schedules is a function of the time interval separating this response from the next reinforcement and does not depend on the presence of responding following the postreinforcement pause or on the contingency that requires a key peck at the end of the interval.

In addition to lengthening the response latency in the associated component of the multiple schedule, increased reinforcement delays also have the effect of decreasing response latency in the other, unchanged, delay component. In the constant $3-\mathrm{sec}$ delay component, the response latency 


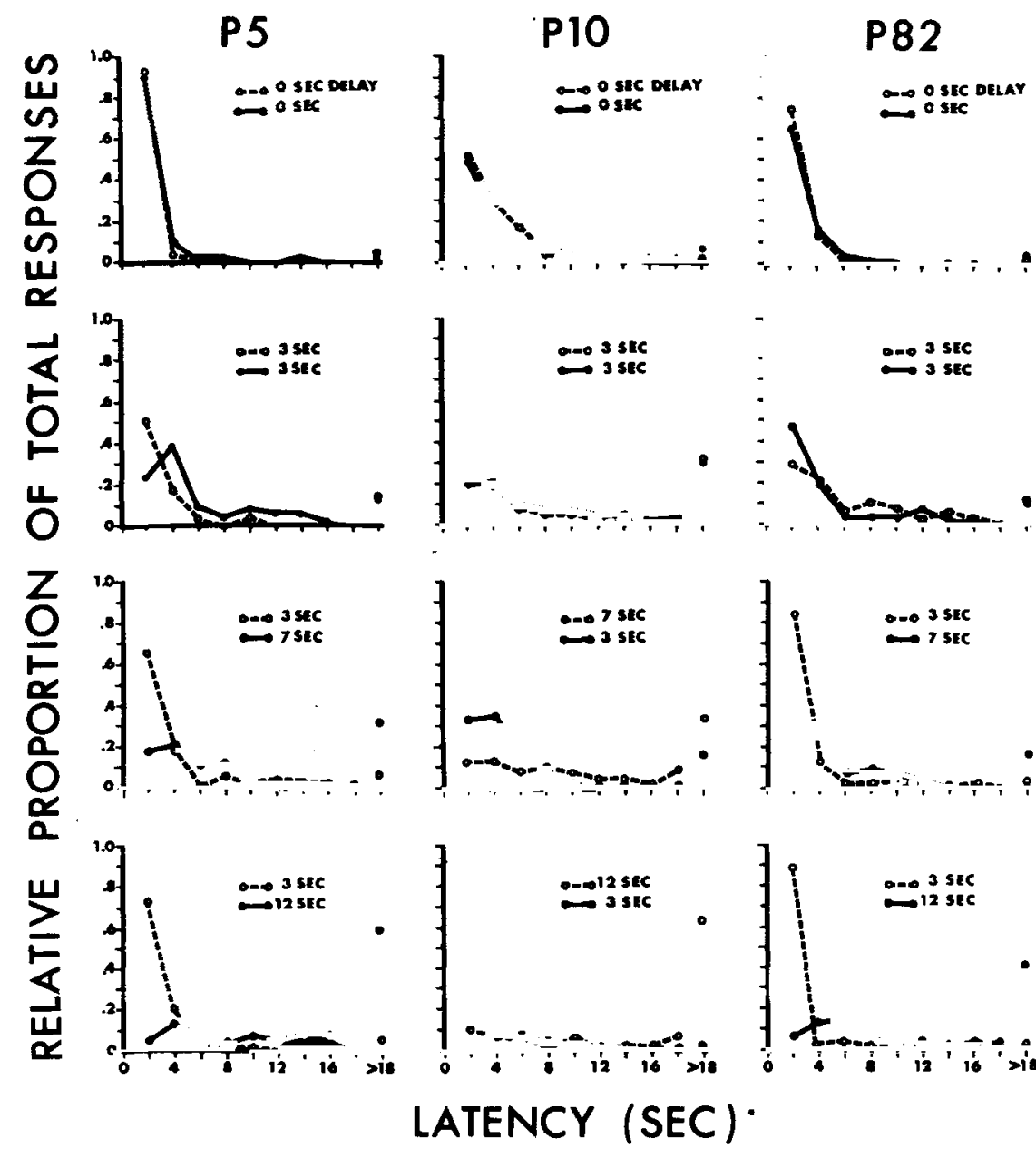

Fig. 1. Relative frequency distributions of response latency for successive reinforcement delays. Solid lines indicate the key light was green; broken lines indicate the light was red. The isolated data points indicate the relative frequency of responses with latencies of $18 \mathrm{sec}$ or more. Each distribution is based on a total of 177 observations obtained in the last three sessions at each set of delay values.

greatly diminishes as the delay associated with the other stimulus is increased from 3 to $12 \mathrm{sec}$. This example of behavioral contrast (Terrace, 1966) is most evident when one of the stimuli is correlated with a 12 -sec delay and the other with a $3-\mathrm{sec}$ delay. Here, for two of the pigeons, the latencies in the $3-\mathrm{sec}$ component are actually shorter than they were under immediate reinforcement.

Both reductions in reinforcement rate in one component of a multiple schedule (Reynolds, 1961a, b; Bloomfield, 1967) and reductions of response rate in that component (Reynolds \& Limpo, 1968; Brownstein \& Hughes, 1970) have been implicated as causes of rate increases in the unchanged schedule component. In the present schedule both of these variables were operating; lengthened delay in tervals reduced reinforcement rate, and, by introducing a period in which responses were "punished" by an extension of the time to reinforcement delivery, they also caused a rate decrease in the associated stimulus component.

A contrast effect like that obtained here was reported by Jenkins (1961) who used a discrete trials discrimination procedure. $\mathrm{He}$ found that as $S$-- responding declined: (1) the frequency of long-latency responses to $\mathrm{S}-$ increased; (2) modal response latency to $\mathbf{S}-$ was generally unchanged; and (3) there was a decrease in the latency of $\mathrm{S}+$ responses as $\mathrm{S}$ - latency increased. The present findings indicate that a stimulus correlated with an increased reinforcement delay, like an $\mathrm{S}$-, has the effect of both slowing responding in its presence and quickening responding in the unchanged schedule component.

All of the pigeons engagen in "superstitious" behavior during the delay intervals. When the delay values differed for the two stimuli, the superstitious behavior patterns also appeared to differ depending on which stimulus was present. Occasionally the birds responded during the delay intervals after the first response and before reinforcement delivery. The incidence of these "extra" responses, which served only to reset the delay timer, did not appear to be correlated with the length of the delay.

\section{REFERENCES}

AZZI, R., FIX, D. S. R., KELLER, F. S., \& ROCHA E SILVA, M. I. Exteroceptive control of response under delayed reinforcement. Journal of the Experimental Analysis of Behavior, 1964, 7, 159-162.

BARRY, J. J., \& HARRISON, J. M. Relation between stimulus intensity and strength of escape responding. Psychological Reports, 1957, 3, 3-8.

BLOOMFIELD, T. M. Behavioral contrast and relative reinforcement frequency in two multiple schedules. Journal of the Experimental Analysis of Behavior, 1967, 10, 151-158.

BROWNSTEIN, A. J., \& HUGHES, R. G. The role of response suppression in behavioral contrast: Signaled reinforcement. Psychonomic Science, 1970, 18, 50-52.

CHUNG, S. H., \& NEURINGER, A. J. Control of responding by a percentage reinforcement schedule. Psychonomic Science, 1967, 8, 25-26.

DEWS, P. B. Free-operant behavior under conditions of delayed reinforcement. 1. CRF-type schedules. Jounal of the Experimental Analysis of Behavior, 1960, 3, 221-234.

DINSMOOR, J. A., HUGHES, L. H., \& MATSUOKA, Y. Escape-from-shock training in a free-response situation. American Journal of Psychology, 1958, 71, 325-337.

JENKINS, H. M. The effect of discrimination training on extinction. Journal of Experimental Psychology, 1961, 61, 111-121.

KELLER, J. V. Delayed escape from light by the albino rat. Journal of the Experimental Analysis of Behavior, 1966, 9, 655-658.

REYNOLDS, G. S. Behavioral contrast. Journal of the Experimental Analysis of Behavior, $1961 \mathrm{a}, 4,57-71$.

REYNOLDS, G. S. Relativity of response rate and reinforcement frequency in a multiple schedule. Journal of the Experimental Analy sis of Behavior, 1961b, 4, 179-184.

REYNOLDS, G. S., \& LIMPO, A. J. On some causes of behavioral contrast. Journal of the Experimental Analysis of Behavior, 1968, 11, 543-547.

SHULL, R. L. A response-initiated fixed-interval schedule of reinforcement. Journal of the Experimental Analysis of Behavior, 1970, 13, 13-15.

SHULL, R. L. Control of post-reinforcement pause duration by fixed-interval schedules of reinforcement: Changing the response-reinforcement contingency. Journal of the Experimental Analysis of Behavior, in press.

SKINNER, B. F. The behavior of organisms. New York: Appleton-Century, 1938.

SKINNER, B. F. Are theorics of learning necessary? Psychological Review, 1950, 57, 193-216.

TERRACE, H. S. Stimulus control. In W. K. Honig (Ed.), Operant behavior: Areas of research and application. New York: Appleton-Century-Crofts, 1966. Pp. 277-344. 